\title{
Practical guidelines to manage discordant situations of SMN2 copy number in patients with spinal muscular atrophy
}

Ivon Cuscó, PhD, * Sara Bernal, PhD, * Laura Blasco-Pérez, MSc, Maite Calucho, MSc, Laura Alias, PhD, Pablo Fuentes-Prior, PhD, and Eduardo F. Tizzano, MD, PhD

Neurol Genet 2020;6:e530. doi:10.1212/NXG.0000000000000530
Correspondence

Dr. Tizzano

etizzano@vhebron.net

\section{Abstract}

\section{Objective}

Assessment of SMN2 copy number in patients with spinal muscular atrophy (SMA) is essential to establish careful genotype-phenotype correlations and predict disease evolution. This issue is becoming crucial in the present scenario of therapeutic advances with the perspective of SMA neonatal screening and early diagnosis to initiate treatment, as this value is critical to stratify patients for clinical trials and to define those eligible to receive medication. Several technical pitfalls and interindividual variations may account for reported discrepancies in the estimation of SMN2 copy number and establishment of phenotype-genotype correlations.

\section{Methods}

We propose a management guide based on a sequence of specified actions once SMN2 copy number is determined for a given patient. Regardless of the method used to estimate the number of SMN2 copies, our approach focuses on the manifestations of the patient to recommend how to proceed in each case.

\section{Results}

We defined situations according to SMN2 copy number in a presymptomatic scenario of screening, in which we predict the possible evolution, and when a symptomatic patient is genetically confirmed. Unexpected discordant cases include patients having a single SMN2 copy but noncongenital disease forms, 2 SMN2 copies compatible with type II or III SMA, and 3 or 4 copies of the gene showing more severe disease than expected.

\section{Conclusions}

Our proposed guideline would help to systematically identify discordant SMA cases that warrant further genetic investigation. The SMN2 gene, as the main modifier of SMA phenotype, deserves a more in-depth study to provide more accurate genotype-phenotype correlations.

\footnotetext{
*These authors are equal contributors with a major role in drafting and revising the manuscript and analyzing the data.

From the Medicine Genetics Group (I.C., L.B.-P., M.C., E.F.T.), Vall dHebron Research Institute (VHIR), Barcelona; Department of Clinical and Molecular Genetics (I.C., L.B.-P., M.C., E.F.T.), Hospital Vall dHebron, Barcelona; Department of Genetics (S.B., L.A.), Hospital de la Santa Creu i Sant Pau, Barcelona; Biomedical Research Institute Sant Pau (IIB Sant Pau) (S.B., L.A.), Hospital de la Santa Creu i Sant Pau, Barcelona; Centro de Investigación Biomédica en Red de Enfermedades Raras (CIBERER-ISCIII, U-705 Barcelona) (S.B., L.A.), Madrid; Molecular Bases of Disease (P.F.-P.), Biomedical Research Institute Sant Pau (IIB Sant Pau), Hospital de la Santa Creu i Sant Pau, Barcelona, Spain. 


\section{Glossary}

FL-SMN = full-length SMN; MLPA = multiplex ligation-dependent probe amplification; NGS = next-generation sequencing; SMA = spinal muscular atrophy; SMN = survival motor neuron; SMN-del7 = SMN2 transcripts lacking exon 7; SNV = single nucleotide variant.

Spinal muscular atrophy (SMA) is a neuromuscular disorder with a global incidence of approximately 1:11,000 live births and a worldwide carrier frequency of $1: 51 .^{1}$ According to age at onset and achieved motor abilities, patients with SMA are usually classified into type I (never sit), II (never walk unaided), or III (achieve independent walking abilities). Independent of the clinical severity, all forms of SMA are caused by loss or homozygous loss-of-function pathogenic variants of the SMN1 gene, located at $5 \mathrm{q} 13$. $^{2,3}$ The number of copies of SMN2, the highly homologous paralog of $S M N 1$, is currently the most important modifier of disease phenotype; in most patients with SMA, this number varies between 1 and $5 .{ }^{4}$ In fact, both SMN1 and $S M N 2$ encode, in principle, the same survival motor neuron $(\mathrm{SMN})$ protein. However, a single $\mathrm{C} \rightarrow \mathrm{T}$ transition in exon 7 disrupts an exon splicing enhancer and/or creates a splicing silencer, and as a consequence, $S M N 2$ works as a hypomorphic allele that produces mainly transcripts lacking exon 7 (SMNdel7). ${ }^{5}$ The SMN-del7 protein is functionally compromised and unstable and therefore rapidly degraded by the ubiquitinproteasome system. ${ }^{6}$ Thus, the SMA phenotype is ultimately due to insufficient levels of full-length SMN (FL-SMN) protein.

On confirmation of biallelic deletion or pathogenic variants of the $S M N 1$ gene in a given patient, the number of $S M N 2$ copies is usually determined and reported. In previous years, this figure was mainly informative and mostly used to elaborate genotype-phenotype correlations rather than to predict a particular phenotype. However, recent advances in SMA therapeutics have strengthened the importance of estimating as accurately as possible the number of SMN2 copies for all patients with SMA. Indeed, whereas genetic confirmation of SMA is relatively straightforward (95\% of the patients can be diagnosed with a simple qualitative test), the assessment of SMN2 copy number requires a quantitative methodology that is not easily implemented in most laboratories. Issues of DNA sample quality, calibration controls, and expertise to resolve ambiguous cases have been previously discussed. ${ }^{4}$ Along these lines, around $40 \%$ of samples recently studied by the same methodology in different laboratories yielded discordant results. ${ }^{7}$ Furthermore, intrinsic biological factors are also a source of discrepancies and add complexity to understanding how a specific SMN2 genotype influences the final phenotype in a given patient. ${ }^{4}$

Numerous studies have shown that the higher the number of copies of SMN2, the larger the amount of FL-SMN protein produced, and thus the milder the associated SMA phenotype. However, this correlation is not absolute, and some patients with 2 copies of SMN2 have mild SMA phenotypes, whereas some with 4 or more copies of the gene have been described as type I or II (reviewed in Calucho et al., 2018). ${ }^{4}$ Thus, accurate estimation of SMN2 copy number is essential in the present scenario of therapeutic advances with 3 specific SMA therapies already approved-nusinersen, onasemnogene abeparvovec, and risdiplam - and with the perspective of SMA neonatal screening and early diagnosis to initiate treatment. ${ }^{8,9}$ We propose a practical guide for the management of discordant SMA cases based on systematic specified actions once SMN2 copy number has been determined for a given patient. Our approach is independent of the method used to estimate SMN2 copy number and focuses on the manifestations of the patient to decide how to proceed in each case.

\section{Methods}

This guideline can be applied to the vast majority of genetically confirmed SMA cases with biallelic deletion of SMN1 and to patients who may need further analysis (e.g., those with hybrid SMN2-SMN1 genes or pathogenic SMN1 variants). We base the current guideline on our previously published meta-analysis of SMA genotype-phenotype correlations and in our continued multidisciplinary experience with patients referred to our consultation, both national (Spain) and international. ${ }^{4}$ Briefly, our approach considers the initial report of SMN2 copy number for a given patient, which is in turn based on a quantitative analysis by multiplex ligation-dependent probe amplification (MLPA) using a mixture of specific probes for the SMA locus (P021-B SMA MLPA kit, a new version of the MLPA kit that includes probes for all exons of the $S M N$ genes, in addition to introns 6 and 7). ${ }^{10,11}$ However, our proposed guide can be applied to any report regardless of the method used for SMN2 analysis. Starting with the estimated SMN2 copy number reported, we then focus on the manifestations of the patient and how to proceed in case of an unexpected discordance. An unambiguous assignment of the SMA type by motor milestones criteria (0 "congenital," I "never sit," II "never walk," or III "walker") was initially widely established for simplicity. However, when necessary, these categories were further refined into subtypes Ia, $b$, and c, IIa and b, IIIa and b, and the milder type IV SMA and even with minimal manifestations, as previously defined. ${ }^{9,12}$ Altogether, we distinguish up to 10 different clinical diagnostic categories to which genetically confirmed cases may be ascribed (table 1) to establish genotype-phenotype correlations and define possible discrepancies.

\section{Data availability}

All data and scripts used to generate the analyses of this article are available on request unless the type of request compromises ethical standards or legal requirements. 
Table 1 Spinal muscular atrophy (SMA) major clinical diagnostic categories in genetically confirmed cases

\begin{tabular}{ll}
\hline $\begin{array}{l}\text { Clinical categories/ } \\
\text { SMA type }\end{array}$ & Main clinical description \\
\hline PS & $\begin{array}{l}\text { Presymptomatic cases (identified at birth by } \\
\text { newborn screening or previous affected sibling) }\end{array}$ \\
\hline 0/la & $\begin{array}{l}\text { Congenital cases/patients with early } \\
\text { manifestations within the first weeks of life }\end{array}$ \\
\hline Ib & Patients with manifestations within first 3 mo of life \\
\hline Ic & Children capable of head control, nonsitters \\
\hline Ila & Sitters who are not able to stand up \\
\hline IIb & $\begin{array}{l}\text { Sitters who are able to stand up, but not to walk } \\
\text { independently }\end{array}$ \\
\hline IIIa & Onset before age 3y, short-term walkers \\
\hline IIlb & Onset after age $3 \mathrm{y}$, long-term walkers \\
\hline IV & Walkers with weakness initiated in adult life \\
\hline MM & $\begin{array}{l}\text { Patients with only MMs (include also } \\
\text { asymptomatics) }\end{array}$ \\
\hline
\end{tabular}

Abbreviations: $\mathrm{MM}=$ minimal manifestation; $\mathrm{PS}=$ presymptomatic. Based on references 4, 9, and 12.

\section{Results}

We defined several discordant situations according to SMN2 copy number in patients with a specific phenotype in 2 different scenarios: (1) presymptomatic diagnosis of a case detected in a newborn screening program or because of a previous SMA family history and (2) when a symptomatic patient is genetically confirmed. The spectrum of possible situations includes from 1 to 4 or more SMN2 copies. A genetically confirmed neonate is considered presymptomatic based mainly on the absence of hypotonia, weakness, hypo- or areflexia, or fasciculations. Other manifestations may be more subtle and therefore not clearly noticeable. ${ }^{9,13}$ In the second scenario, according to the patient's phenotype, different discrepancies are discussed. We defined recommendations according to the reported literature and our own experience, as follows.

\section{Guideline in a neonatal screening: asymptomatic context}

The different situations that could be encountered when facing a presymptomatic patient, the number of SMN2 copies, the predicted phenotypes and suggested actions in each situation, and their rationale are given in table 2. Patients with 1 SMN2 copy usually present a congenital SMA form, and the discordance refers to their presenting without symptoms in the neonatal period. On the other hand, an apparently normal neonate should be expected to have at least 2 SMN2 copies, and different predictions and actions are endorsed.

\section{Guidelines in a symptomatic context}

The different situations of symptomatic patients, the number of SMN2 copies, the observed phenotypes and the rationale, and actions suggested in each case are summarized in table 3. Unexpected discordant cases include patients having (1) a single SMN2 copy but noncongenital disease forms (types Ib, II, or even III), (2) 2 SMN2 copies with type II or III SMA, (3) 3 copies of the gene with severe disease forms (type Ia and b), and (4) at least 4 SMN2 copies but more severe SMA (types I or II).

\section{Discussion}

We have developed a practical guide for management and advice to help in the interpretation and resolution of discordant SMA cases according to the number of SMN2 copies and phenotype. Our approach applies to virtually all genetically confirmed cases and is independent of the method used to determine SMN2 copy number (table 4), but focuses instead on the manifestations of the patient. We suggest several recommendations to rapidly define the course of actions for a given SMA patient. SMN2 copy number estimation is essential to establish accurate genotype-phenotype correlations, to predict disease evolution, to stratify patients for clinical trials, and to define those eligible for a given treatment. However, in some patients, this information may be insufficient to correlate with the observed phenotype. So far, the number of copies of the $S M N 2$ gene and the presence of rare $S M N 2$ variants (e.g., NM 017411.3:c.859G>C and NM_017411.3:c.835-44A>G) remain the major modifiers of SMA disease phenotype. ${ }^{14-17}$

The main characteristics of methods currently used to quantitate SMN2 copies (TaqMan, LightCycler, MLPA, PCR-CE, and digital PCR) are given in table $4{ }^{10,11,18-29}$ In a metaanalysis of 33 studies published from 1999 to 2017, in which SMN2 copy number was reported for a total of 3,393 patients with SMA, MLPA was used in 54\% of patients $(\mathrm{n}=1870)$ followed by LightCycler in 21.4\% $(\mathrm{n}=741)$ and TaqMan in $6.5 \%(\mathrm{n}=228)$ and fewer patients with the remaining methodologies. ${ }^{4,22,27}$ All these different methodologies have advantages and disadvantages, and there are technical aspects beyond the method itself that have to be considered such as DNA sample quality and interpretation and control issues. Digital PCR approaches ${ }^{28}$ and novel protocols using nextgeneration sequencing (NGS) may help with the resolution of particularly difficult cases. Noteworthy, NGS methodologies allow a thorough analysis of $S M N 2$ copies at the genomic level including also introns and allowing a better investigation of the equivalency and quality of the $S M N 2$ copies. In addition, NGS provides valuable information that may be validated to establish more comprehensive genotype-phenotype correlations. ${ }^{19-21}$

A virtually asymptomatic neonate with a single $S M N 2$ copy is an obviously unexpected situation. As indicated in table 2, congenital type 0 cases have only 1 SMN2 copy, which is insufficient to rescue the phenotype of the disease at the prenatal stage. In these patients, SMA manifests usually at 
Table 2 Suggested course of actions in SMA cases identified during newborn screening

\begin{tabular}{|c|c|c|c|c|}
\hline $\begin{array}{l}\text { SMN2 } \\
\text { copy } \\
\text { number }\end{array}$ & $\begin{array}{l}\text { Manifestations } \\
\text { at birth (clinical } \\
\text { category) }\end{array}$ & $\begin{array}{l}\text { Expected } \\
\text { correlation }\end{array}$ & Rationale for recommended actions & $\begin{array}{l}\text { Recommended actions and expected } \\
\text { phenotype }\end{array}$ \\
\hline 1 & $\begin{array}{l}\text { Not observed } \\
\text { (PS) }\end{array}$ & $\mathrm{No}^{\mathrm{a}}$ & $\begin{array}{l}\text { Presence of only } 1 \text { SMN2 copy is usually associated } \\
\text { with congenital SMA. If a child is asymptomatic at } \\
\text { birth and remains so for the first weeks of life, this } \\
\text { would suggest an error in the previous SMN2 } \\
\text { quantitation or the presence of a positive modifier } \\
\text { single nucleotide variant in the single gene copy. }\end{array}$ & $\begin{array}{l}\text { Retest for } S M N 2 \text { copy number with a new sample } \\
\text { and/or consider another method/laboratory. If the } \\
\text { presence of a single } S M N 2 \text { copy is confirmed, test } \\
\text { for rare positive variants associated with better- } \\
\text { than-expected phenotypes (e.g., c. } 859 \mathrm{G}>\mathrm{C}^{\mathrm{b}} \text { and } \\
\text { c.835- } 44 \mathrm{~A}>\mathrm{G} \text { ), e.g., by Sanger sequencing, or } \\
\text { perform next-generation sequencing (NGS) } \\
\text { analysis. }^{19-21}\end{array}$ \\
\hline
\end{tabular}

\begin{tabular}{ll}
\hline 2 & $\begin{array}{l}\text { Not observed } \\
\text { (PS) }\end{array}$
\end{tabular}

Neonates with $2 S M N 2$ copies usually have a normal appearance. There is a latency period in which SMA symptoms may not be detectable. However, subtle manifestations of the disease might appear shortly after birth.

Test for rare positive variants in SMN2 associated with better-than-expected phenotypes (e.g., c. $859 \mathrm{G}>C^{\mathrm{b}}$ and c.835-44A $>\mathrm{G}$ ). If negative, the patient has $>90 \%$ probability of developing severe, type I SMA. ${ }^{4}$ If positive, the patient will be virtually a sitter or walker later in their life ${ }^{4,14}$

\begin{tabular}{|c|c|c|c|}
\hline 3 & $\begin{array}{l}\text { Not observed } \\
\text { (PS) }\end{array}$ & Yes & $\begin{array}{l}\text { Neonates with } 3 \text { SMN2 copies have a normal } \\
\text { appearance and usually without manifestations at } \\
\text { least for the first } 3 \text { mo of life. }\end{array}$ \\
\hline
\end{tabular}

Test for rare positive variants in SMN2 associated with better-than-expected phenotypes (e.g., c. $859 \mathrm{G}>\mathrm{C}^{\mathrm{b}}$ and c.835-44A $>\mathrm{G}$ ). If negative, the patient has about $60 \%$ probability of developing type II disease, 35\% type III, and 5\% type Ic. Similar Bayesian estimations can also be calculated. ${ }^{4,25}$ If positive, the patient will be virtually a walker later in their life ${ }^{4,14}$

\begin{tabular}{|c|c|c|c|}
\hline$\geq 4$ & $\begin{array}{l}\text { Not observed } \\
\text { (PS) }\end{array}$ & Yes & $\begin{array}{l}\text { Neonates with } 4 \text { SMN2 copies have a normal } \\
\text { appearance. About } 14 \% \text { of SMA cases worldwide } \\
\text { have } 4 \text { SMN2 copies. }{ }^{4}\end{array}$ \\
\hline
\end{tabular}

Retest for SMN2 copy number with a new sample and/or consider another method/laboratory. If copy number is confirmed, the patient has $>90 \%$ probability of being a walker later in their life (SMA types III or IV). ${ }^{4}$ Test for the rare positive variants is an option.

Abbreviations: $\mathrm{PS}=$ presymptomatic; $\mathrm{SMA}=$ spinal muscular atrophy.

${ }^{a}$ In this case, the expected category would be congenital (see text for further details and discussion). Percentages are calculated according to reference 4. ${ }^{\mathrm{b}} \mathrm{A}$ commercial test is available for the c.859G $>\mathrm{C}$ variant (table 4).

birth with at least marked hypotonia and weakness, but more commonly with a complex clinical picture that includes in addition respiratory problems, contractures, cardiac malformation, vascular necrosis, ${ }^{30}$ and diffuse and progressive brain abnormalities. ${ }^{31}$ If the patient does not manifest any of these symptoms, the most likely explanation is an erroneous determination of SMN2 copy number, which should be excluded. Retesting with a new DNA sample, eventually using a different method or performing the analysis in a different laboratory, might solve the issue. However, if the presence of only 1 SMN2 copy is confirmed, it is possible that single nucleotide variants (SNVs) of this single gene copy or a potential SMN2-SMN1 hybrid structure ${ }^{32}$ make it functionally superactive, i.e., capable of generating more full-length mRNA transcripts and FL-SMN protein than wild-type SMN2 and thus to at least partly rescue the phenotype. Thus, testing for known positive variants such as NM_017411.3:c.859G $>C^{16}$ and NM_017411.3:c.835-44A $>\mathrm{G}^{15}$ is recommended. If negative, it would be interesting to conduct an SMN2 NGS study of the patient to unravel changes that may act as positive modifiers of disease severity. Along these lines, at least 10 SMA cases with 1 SMN2 copy and type II or even III disease have been reported or personally communicated to date. ${ }^{4,33}$ Unfortunately, these apparently discrepant cases have not been further studied, and it remains to be seen whether these phenotype-genotype discrepancies are due to technical or biological reasons.

Genetically confirmed SMA cases of newborns with 2 SMN2 copies have a high probability (>90\%) of developing type I disease, but they usually have a normal appearance at birth. There is a latency period-from 1 to several weeks_in which clear symptoms of weakness and hypotonia may not be detectable. However, subtle or less evident manifestations may appear early after birth such as hypo- or areflexia, weak cry, diaphragmatic breathing, feeding problems, and dysautonomic manifestations (i.e., increase of sweating and irregular skin responses to temperature changes). ${ }^{9}$ On the other hand, exceptional cases with 2 SMN2 copies may manifest overt disease at birth as usually occurs in type 0 cases. ${ }^{34}$ Thus, and considering the continuous spectrum of phenotypes in SMA, it would be difficult to differentiate between congenital type 0 and type Ia disease, and both categories could be merged into type $0 /$ Ia disease. ${ }^{12}$

To better predict the evolution of patients with 2 SMN2 copies, it would be advisable to test for the presence of rare positive variants mentioned above. Indeed, in our experience, around $40 \%$ of cases with 2 SMN2 copies and a milder phenotype (types II or III) may harbor one of these SNVs. ${ }^{4,14}$ 
Table 3 Suggested course of actions in symptomatic SMA cases, for whom phenotypes and genotypes are not correlated (see text for further details and discussion)

\begin{tabular}{llll}
\hline $\begin{array}{l}\text { SMN2 } \\
\text { copy } \\
\text { number }\end{array}$ & $\begin{array}{l}\text { Observed } \\
\text { manifestations/ } \\
\text { milestones clinical } \\
\text { category }\end{array}$ & $\begin{array}{l}\text { Expected } \\
\text { clinical } \\
\text { category }\end{array}$ & Rationale for recommended actions \\
\hline $\mathbf{1}$ & $\begin{array}{l}\text { Patients with type I, } \\
\text { II, or III SMA }\end{array}$ & & $\begin{array}{l}\text { Patients with 1 SMN2 copy usually present } \\
\text { congenital SMA. Patients with typical type I, II, or } \\
\text { even III disease forms might point to an error in the } \\
\text { initial SMN2 copy number determination or to the } \\
\text { presence of a positive modifier in their single SMN2 } \\
\text { copy. }\end{array}$
\end{tabular}

\section{Recommended actions}

Retest for SMN2 copy number with a new sample and/or consider another method/laboratory. If the presence of a single SMN2 copy is confirmed, test for SNVs in the gene that have been previously associated with better-than-expected phenotypes (e.g., c.859G $>C^{a}$ and c.835-44A>G), e.g., by Sanger sequencing, or perform nextgeneration sequencing (NGS) analysis. ${ }^{19-21}$

Retest for SMN2 copy number with a new sample and/or consider another method/laboratory. If confirmed, test for rare variants in SMN2 that have been previously associated with betterthan-expected phenotypes (e.g., c.859G $>C^{a}$ and c.835-44A>G). If negative, perform NGS analysis to detect novel SNVs or other changes that could be positive modifiers of disease severity. ${ }^{19-21}$

\begin{tabular}{lll}
\hline 3 & $\begin{array}{l}\text { Type I cases with } \\
\text { disease onset } \\
\text { before the age of } 3 \\
\text { mo (la; lb) }\end{array}$ & Ic, Ila, IIb,
\end{tabular}$\quad \begin{aligned} & \text { Type Ic cases usually manifest disease between } 3 \\
& \text { and } 6 \text { mo of life, and have } 3 \text { SMN2 copies. A typical } \\
& \text { type Ib patient has } 2 \text { copies of the gene. Three } \\
& \text { copies are also detected in type II and III patients. }\end{aligned}$

Retest for SMN2 copy number with a new sample and/or consider another method/laboratory. If SMN2 copy number is confirmed, perform further studies to identify SNVs or partial intragenic deletions that could act as negative phenotype modifiers (e.g., complete MLPA, ${ }^{11} \mathrm{NGS}^{19-21}$ ).

Retest for SMN2 copy number with a new sample and/or consider another method/laboratory. If SMN2 copy number is confirmed, perform further studies to identify SNVs or partial intragenic deletions that could act as negative phenotype modifiers (e.g., complete MLPA, ${ }^{11} \mathrm{NGS}^{19-21}$ ).

Abbreviations: MLPA = multiplex ligation-dependent probe amplification; $M M$ = minimal manifestation; NGS = next-generation sequencing; SMA = spinal muscular atrophy; SNV = single nucleotide variant.

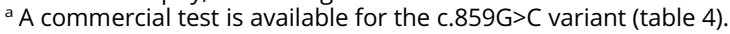

Negative variants in SMN2 have not been discovered, but warrant further investigation.

In patients with 3 SMN2 copies, our previous meta-analysis revealed that about $60 \%$ of cases develop type II disease, $35 \%$ type III, but $5 \%$ still had the more severe type Ic SMA. ${ }^{4}$ Therefore, all neonates with 3 gene copies would be expected to have a normal appearance and to remain essentially asymptomatic at least for the first 3 months of life. The NURTURE study of presymptomatic patients with 2 or $3 S M N 2$ copies treated with nusinersen has shown that patients with 3 gene copies treated in the neonatal period have in general a better evolution. ${ }^{13}$ Again, here it is advisable to check for rare positive variants to better predict the expected outcomes.

The treatment recommendations for presymptomatic cases with 4 SMN2 copies are still an evolving issue. ${ }^{8,35,36}$ Based on available evidence, and in the absence of a reliable biomarker of disease evolution, in the United States, it has been recently recommended to initiate treatment of all infants with 4 copies of SMN2. ${ }^{35}$ In our meta-analysis of 3,393 cases, patients with 4 copies accounted for less than $14 \%$ of all reported SMA cases. ${ }^{4}$ In the light of this finding, it is rather surprising that in a recent pilot newborn screening study, 15 of 37 detected cases (40\%) had 4 SMN2 copies. ${ }^{36}$ Excluding technical issues with SMN2 quantitation, if these results are reproduced in other newborn screening studies, it would be tempting to speculate that a certain number of individuals in the general population with 0,4 genotype (i.e., no SMN1 gene but 4 SMN2 copies) remain with minimal symptoms or asymptomatic throughout their lives and thus undetected. Preliminary results of the SMA newborn screening program in Australia reported 9 positive cases, but none had 4 SMN2 copies. ${ }^{37}$ It is important to highlight that copy number studies in positive patients detected by newborn screening should be performed in expertise centers and with a validated methodology. In the shared decision to immediately start treatment of neonates with 4 SMN2 copies or delay the initiation of treatment, several alternatives-each with advantages and disadvantages-have to be considered (outlined in table 5). Whatever decision is taken, it is important to recall that disease onset in these patients before the first year of life is rather unlikely, giving the health care team and the parents more time to weigh advantages and disadvantages of each 
Table 4 Major features of the more commonly used methods to determine SMN2 copy number

\begin{tabular}{ll}
\hline Method & Main characteristics \\
\hline $\begin{array}{l}\text { Real-time PCR } \\
\text { (TaqMan }\end{array}$ & Multiplex TaqMan real-time quantitative \\
platform) & PCR assay.
\end{tabular}

Advantages

Fast, robust, and sensitive technique. Low cost. Requires only small amounts of DNA. Easy interpretation of results by automated variant reporting software. DNA quality important, but not as limiting as in other techniques. Neither a standard curve nor control samples are necessary.

Low cost. Easy interpretation of results by automated variant reporting software.

Quantitative assay on the basis of realtime PCR, performed with a LightCycle instrument (Roche Diagnostics, Basel, Switzerland) by using the fluorescence resonance energy transfer technique (PCR products are based on the use of SYBR Green).

$\begin{array}{ll}\begin{array}{l}\text { Real-time PCR } \\ \text { (LightCycler }\end{array} & \begin{array}{l}\text { Quantitative assay on the basis of real- } \\ \text { platform) }\end{array} \\ & \text { time PCR, performed with a LightCycler } \\ & \text { instrument (Roche Diagnostics, Basel, } \\ & \text { Switzerland) by using the fluorescence } \\ & \text { resonance energy transfer technique (PCR } \\ \text { products are based on the use of SYBR } \\ \text { Green). }\end{array}$

Multiple ligationdependent probe amplification, version $\mathrm{B} 1^{10,11,27}$
Variation of the multiplex PCR assay that permits amplification of multiple target genes with a single primer pair. Quantitates gene doses.
Low cost. Robust and sensitive. Requires only small amounts of DNA and its quality is not as limiting as in other techniques. Does not require sophisticated logistic (a therrmocycler and a vertical electrophoresis sequencer). Easy interpretation of results by automated variant reporting, free software (Coffalyser). SMN1 and SMN2 exons analyzed in the same experiment, detection of exonic hybrid genes, and partial intragenic deletions. False positive deletions may result from mutations located in regions of hybridization of the probes
Disadvantages

Assays are performed in triplicate and an internal control is necessary to normalize results, as the method is based on relative quantitation. Only the number of copies of SMN2 exon 7 is determined. Real-time PCR technology is not always available in a routine laboratory.

As a relative quantitative assay, it requires standard curves to normalize results. DNA quality is limiting, large amounts of DNA are necessary, and the process is laborious. Only the number of copies of SMN2 exon 7 is determined.

As a relative quantitative assay, normalization of results is necessary, for which control samples are required. Long assay time (24 h minimum).
Robust and sensitive technique. Requires only small amounts of DNA. Simple and rapid workflow (<4 h). Does not require sophisticated technology or structural logistics (a thermocycler and a vertical electrophoresis sequencer). Easy interpretation of results by automated variant reporting software. Scalable design that allows the study of additional variants, such as hybrid genes, silent carriers, and 1 SMN2 modifier variant (PLUS KIT).
As a relative quantitative assay, normalization is necessary, which requires calibration samples. Analysis limited to exon 7 of SMN1 and SMN2 genes, therefore unable to detect partial deletions.

\begin{tabular}{|c|c|c|c|}
\hline $\begin{array}{l}\text { Droplet digital } \\
\text { PCR (ddPCR) } \\
18,28,29\end{array}$ & $\begin{array}{l}\text { DNA is partitioned into thousands of } \\
\text { droplets that are subsequently amplified, } \\
\text { and fluorescently labeled probe signals } \\
\text { within each droplet are recorded as either } \\
\text { positive or negative, depending on the } \\
\text { presence or absence of a nucleotide } \\
\text { target. }\end{array}$ & $\begin{array}{l}\text { Eliminates the need for standard curves by } \\
\text { using references or endogenous controls. } \\
\text { As an absolute quantitation method of } \\
\text { exons } 7 \text { and } 8 \text { in SMN1 or SMN2, there is no } \\
\text { need for normalization. Requires } \\
\text { extremely low DNA concentrations (e.g., } \\
\text { from dried blood spots). }\end{array}$ & $\begin{array}{l}\text { The special technology necessary to } \\
\text { perform ddPCR is not available in most } \\
\text { laboratories. High costs limit } \\
\text { determination of the copy number of all } \\
\text { SMN2 exons. Therefore, partial } \\
\text { intragenic SMN2 deletions are not } \\
\text { detected. }\end{array}$ \\
\hline $\begin{array}{l}\text { Next-generation } \\
\text { sequencing (NGS) } \\
\text { 19-21 }\end{array}$ & $\begin{array}{l}\text { Non-Sanger-based high-throughput DNA } \\
\text { sequencing technologies (several } \\
\text { platforms are currently available). }\end{array}$ & $\begin{array}{l}\text { Allows analysis of complete genes (exons } \\
\text { and introns) and to detect } \\
\text { rearrangements and point mutations. }\end{array}$ & $\begin{array}{l}\text { Not available in several diagnostic } \\
\text { laboratories. Laborious process and } \\
\text { longer assay times. Interpretation of } \\
\text { results requires specialized } \\
\text { bioinformatics tools and usually a } \\
\text { bioinformatician. Quantitative studies } \\
\text { using NGS are not very robust when } \\
\text { SMN1 and SMN2 genes coexist due to } \\
\text { their extremely high homology. }\end{array}$ \\
\hline
\end{tabular}

therapeutic alternative. Some parents may want to move forward without further testing, but it is crucial that an expert team adequately communicates about the disease and manages their expectations. ${ }^{8}$ The implementation of neonatal screening in different regions will help to better define protocols of follow-up and validate biomarkers of disease progression such as levels of plasma phosphorylated neurofilament heavy chain in these patients. ${ }^{38}$
Different approaches should be considered when dealing with symptomatic cases. Here, most of the discrepancies should be initially faced with a retesting of the patient with a new sample, a different method or even in a second laboratory. According to the results of this second test, it might be advisable to continue testing for known variants in SMN2. A recent SMA test that includes testing for the NM_017411.3:c.859G $>$ C variant has been made commercially available (table 4) 
Table 5 Factors to be considered when deciding to treat neonates with genetically confirmed spinal muscular atrophy with 4 SMN2 copies

\begin{tabular}{lll}
\hline Factors to consider & Treat presymptomatically & Treat when symptoms appear \\
\hline $\begin{array}{l}\text { Disease appearance and } \\
\text { complications }\end{array}$ & Avoid possible long-term disease complications & Risk of long-term disease complications \\
\hline $\begin{array}{l}\text { Opportunity of treatment } \\
\text { Time to initiate therapy }\end{array}$ & $\begin{array}{l}\text { Some patients might be unnecessarily treated } \\
\text { for a long time }\end{array}$ & Depends on rescue of disease manifestations \\
\hline $\begin{array}{l}\text { Adverse events when } \\
\text { continuous therapy }\end{array}$ & Risk of treatment complications & Therapeutic window might be too short or lost \\
\hline Economic aspects & Higher cost of therapy & Reduced risk of treatment complications \\
\hline Quality of life (QoL) issues & Effect of years of treatment on QoL & Higher cost of managing morbidity \\
\hline Parent and family expectations & Unease of treating a healthy baby & Effect of disease on QoL \\
\hline
\end{tabular}

(asuragen.com). Furthermore, a new version of the SMA MLPA kit including all exons of the SMN1 and SMN2 genes has been reported. This new version of the kit would allow detection of some intragenic or $5^{\prime}$ terminal deletions that were previously extremely difficult to detect. ${ }^{11}$ However, not all cases might be resolved with an accurate SMN2 copy number assessment or checking for known variants by Sanger sequencing. If the results of all these studies are not categorical, SMN2 NGS studies should be considered to determine whether the SMN2 copies are functionally identical (table 4). ${ }^{19-21}$

Certainly, the SMN2 gene, as the main modifier of SMA phenotype, deserves a more in-depth study beyond the current standard copy number determination. We believe that in terms of its impact on SMA phenotype, SMN2 copy number might be considered as the tip of an iceberg of which other genetic and epigenetic features, most notably SNVs, represent the submerged part with relevant effects to phenotype of the patients with SMA (figure). A number of other genes have been proposed as candidate modifiers of the SMA phenotype including methylation status of SMN2 (reviewed in Maretina et al., 2018), ${ }^{39}$ although none of them are yet validated in clinical practice. Given that SMN2 variants modify the disease phenotype and that transcripts derived from SMN2 are targets for splicing modifiers in the therapeutic scenario, it is essential to gain a thorough insight into the complete SMN2 sequences of discordant patients. Furthermore, we need to unveil possible linkages between specific $S M N 2$ variants and factors involved in SMN2 splicing, on the one hand, and responses to treatment, on the other hand. In patients receiving expensive treatments, their efficacy should be periodically assessed to decide whether to continue treatment or to look for alternatives. Responses to treatment may vary in patients with SMA (from responders to slow responders to nonresponders) ${ }^{40}$ but it is currently unknown whether specific features of their SMN2 genes are directly correlated with these responses. Discovery and validation of positive and negative genetic markers remain thus an urgent matter in SMA research. New SMA classifications may need to be adopted in line with the current scenario of early genetic diagnosis, therapeutic intervention, and evolving phenotypes. ${ }^{41}$ In this context, time to development of different manifestations and age at treatment initiation are becoming crucial as predictors of the trajectory of the disease. ${ }^{9,42}$ In this envisaged perspective, a better and clearer definition of the SMN2 genotype (copies and sequence) in each patient would be extremely relevant. Along these lines, our proposed guideline would help to systematically and rigorously identify discordant SMA cases that warrant further genetic investigation.

\section{Acknowledgment}

The authors thank all colleagues for their confidence, information, and reference of patients for study.

Figure The iceberg representation of the genetic factors that influence SMA phenotype

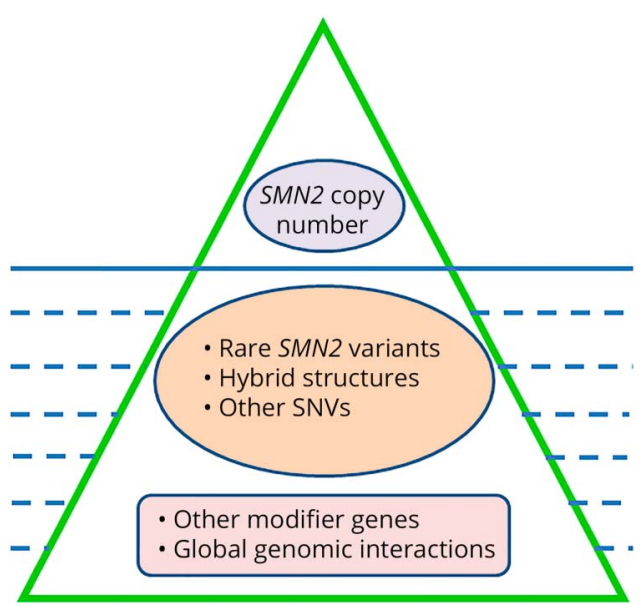

SMN2 copy number might be considered as the tip of an iceberg of which other SMN2 genetic and epigenetic features, most notably SMN2 SNVs, represent the submerged part. Other modifier genes and whole genomic data may complete possible influences. SMA = spinal muscular atrophy; SNV = single nucleotide variant. 


\section{Study funding}

This work was partially supported by grants from Fundación Daniel Bravo Andreu (to E.F.T. and P.F.-P. and supporting M.C.), SMA Europe (to E.F.T. and P.F.-P.), Biogen, and Spanish Instituto de Salud Carlos III, Fondo de Investigaciones Sanitarias and cofunded with ERDF funds (grant no. FIS PI18/000687) to E.F.T. and L.A.

\section{Disclosure}

E.F. Tizzano discloses grant support to conduct CTs on SMA from Ionis/Biogen and serves as a consultant to AveXis, Novartis, Biogen, Biologix, Cytokinetics, and Roche. The other authors report no disclosures relevant to the manuscript. Go to Neurology.org/NG for full disclosures.

\section{Publication history}

Received by Neurology: Genetics June 23, 2020. Accepted in final form September 29, 2020.

\section{Appendix Authors}

\begin{tabular}{|c|c|c|}
\hline Name & Location & Contribution \\
\hline $\begin{array}{l}\text { Ivon } \\
\text { Cuscó, } \\
\text { PhD }\end{array}$ & $\begin{array}{l}\text { Medicine Genetics Group, } \\
\text { Vall d'Hebron Research } \\
\text { Institute (VHIR); Department } \\
\text { of Clinical and Molecular } \\
\text { Genetics, Hospital Vall } \\
\text { dHebron, Barcelona, Spain }\end{array}$ & $\begin{array}{l}\text { Drafting/revision of the } \\
\text { manuscript for content, } \\
\text { including medical writing } \\
\text { for content, and major role } \\
\text { in the acquisition of data }\end{array}$ \\
\hline $\begin{array}{l}\text { Sara } \\
\text { Bernal, } \\
\text { PhD }\end{array}$ & $\begin{array}{l}\text { Department of Genetics, } \\
\text { Biomedical Research } \\
\text { Institute Sant Pau (IIB Sant } \\
\text { Pau), Hospital de la Santa } \\
\text { Creu i Sant Pau, Barcelona; } \\
\text { Centro de Investigación } \\
\text { Biomédica en Red de } \\
\text { Enfermedades Raras } \\
\text { (CIBERER-ISCIII, U-705 } \\
\text { Barcelona), Madrid, Spain }\end{array}$ & $\begin{array}{l}\text { Drafting/revision of the } \\
\text { manuscript for content, } \\
\text { including medical writing } \\
\text { for content, and major role } \\
\text { in the acquisition of data }\end{array}$ \\
\hline
\end{tabular}

\begin{tabular}{|c|c|c|}
\hline $\begin{array}{l}\text { Laura } \\
\text { Blasco- } \\
\text { Pérez, MSc }\end{array}$ & $\begin{array}{l}\text { Medicine Genetics Group, } \\
\text { Vall dHebron Research } \\
\text { Institute (VHIR); } \\
\text { Department of Clinical } \\
\text { and Molecular Genetics, } \\
\text { Hospital Vall dHebron, } \\
\text { Barcelona, Spain }\end{array}$ & $\begin{array}{l}\text { Drafting/revision of the } \\
\text { manuscript for content, } \\
\text { including medical writing } \\
\text { for content }\end{array}$ \\
\hline $\begin{array}{l}\text { Maite } \\
\text { Calucho, } \\
\text { MSc }\end{array}$ & $\begin{array}{l}\text { Medicine Genetics Group, } \\
\text { Vall dHebron Research } \\
\text { Institute (VHIR) } 08035 \\
\text { Barcelona, Spain. } \\
\text { Department of Clinical } \\
\text { and Molecular Genetics, } \\
\text { Hospital Vall dHebron, } \\
08035 \text { Barcelona, Spain }\end{array}$ & $\begin{array}{l}\text { Drafting/revision of the } \\
\text { manuscript for content, } \\
\text { including medical writing } \\
\text { for content }\end{array}$ \\
\hline $\begin{array}{l}\text { Laura } \\
\text { Alias, PhD }\end{array}$ & $\begin{array}{l}\text { Department of Genetics, } \\
\text { Biomedical Research } \\
\text { Institute Sant Pau (IIB Sant } \\
\text { Pau), Hospital de la Santa } \\
\text { Creu i Sant Pau, Barcelona; } \\
\text { Centro de Investigación } \\
\text { Biomédica en Red de } \\
\text { Enfermedades Raras } \\
\text { (CIBERER-ISCIII, U-705 } \\
\text { Barcelona), Madrid, Spain }\end{array}$ & $\begin{array}{l}\text { Analysis or interpretation of } \\
\text { data }\end{array}$ \\
\hline
\end{tabular}

Appendix (continued)

\begin{tabular}{|c|c|c|}
\hline Name & Location & Contribution \\
\hline $\begin{array}{l}\text { Pablo } \\
\text { Fuentes- } \\
\text { Prior, PhD }\end{array}$ & $\begin{array}{l}\text { Molecular Bases of Disease, } \\
\text { Biomedical Research } \\
\text { Institute Sant Pau (IIB Sant } \\
\text { Pau), Hospital de la Santa } \\
\text { Creu i Sant Pau, Barcelona, } \\
\text { Spain }\end{array}$ & $\begin{array}{l}\text { Drafting/revision of the } \\
\text { manuscript for content, } \\
\text { including medical writing } \\
\text { for content, and major role } \\
\text { in the acquisition of data }\end{array}$ \\
\hline $\begin{array}{l}\text { Eduardo F. } \\
\text { Tizzano, } \\
\text { MD, PhD }\end{array}$ & $\begin{array}{l}\text { Medicine Genetics Group, } \\
\text { Vall dHebron Research } \\
\text { Institute (VHIR); Department } \\
\text { of Clinical and Molecular } \\
\text { Genetics, Hospital Vall } \\
\text { dHebron, Barcelona, Spain }\end{array}$ & $\begin{array}{l}\text { Drafting/revision of the } \\
\text { manuscript for content, } \\
\text { including medical writing } \\
\text { for content; major role in } \\
\text { the acquisition of data; and } \\
\text { study concept or design }\end{array}$ \\
\hline
\end{tabular}

\section{References}

1. Sugarman EA, Nagan N, Zhu H, et al. Pan-ethnic carrier screening and prenatal diagnosis for spinal muscular atrophy: clinical laboratory analysis of $>72,400$ specimens. Eur J Hum Genet 2012;20:27-32.

2. Wirth B. An update of the mutation spectrum of the survival motor neuron gene (SMN1) in autosomal recessive spinal muscular atrophy (SMA). Hum Mutat 2000, 15:228-237.

3. Alías L, Bernal S, Fuentes-Prior P, et al. Mutation update of spinal muscular atrophy in Spain: molecular characterization of 745 unrelated patients and identification of four novel mutations in the SMN1 gene. Hum Genet 2009;125:29-39.

4. Calucho M, Bernal S, Alías L, et al. Correlation between SMA type and SMN2 copy number revisited: an analysis of 625 unrelated Spanish patients and a compilation of 2834 reported cases. Neuromuscul Disord 2018;28:208-215.

5. Monani UR, Lorson CL, Parsons DW, et al. A single nucleotide difference that alters splicing patterns distinguishes the SMA gene SMN1 from the copy gene SMN2. Hum Mol Genet 1999;8:1177-1183.

6. Vitte J, Fassier C, Tiziano FD, et al. Refined characterization of the expression and stability of the SMN gene products. Am J Pathol 2007;171:1269-1280.

7. Schorling DC, Becker J, Pechmann A, Langer T, Wirth B, Kirschner J. Discrepancy in redetermination of SMN2 copy numbers in children with SMA [online]. Neurology 2019;93:267-269.

8. Dangouloff T, Burghes A, Tizzano EF, et al. 244th ENMC international workshop: newborn screening in spinal muscular atrophy May 10-12, 2019, Hoofddorp, the Netherlands. Neuromuscul Disord 2020;30:93-103.

9. Tizzano EF. Treating neonatal spinal muscular atrophy: a 21st century success story? Early Hum Dev 2019;138:104851.

10. Alías L, Bernal S, Barceló MJ, et al. Accuracy of marker analysis, quantitative real-time polymerase chain reaction, and multiple ligation-dependent probe amplification to determine SMN2 copy number in patients with spinal muscular atrophy. Genet Test Mol Biomarkers 2011;15:587-594.

11. Vijzelaar R, Snetselaar R, Clausen M, et al. The frequency of SMN gene variants lacking exon 7 and 8 is highly population dependent. PLoS One 2019;14:e220211.

12. Talbot K, Tizzano EF. The clinical landscape for SMA in a new therapeutic era. Gene Ther 2017;24:529-533.

13. De Vivo DC, Bertini E, Swoboda KJ, et al. Nusinersen initiated in infants during the presymptomatic stage of spinal muscular atrophy: interim efficacy and safety results from the Phase 2 NURTURE study. Neuromuscul Disord 2019;29:842-856.

14. Bernal S, Alías L, Barceló MJ, et al. The c.859G $>$ C variant in the SMN2 gene is associated with types II and III SMA and originates from a common ancestor. J Med Genet 2010;47:640.

15. Wu X, Wang SH, Sun J, Krainer AR, Hua Y, Prior TW. A-44G transition in SMN2 intron 6 protects patients with spinal muscular atrophy. Hum Mol Genet 2017;26:2768-2780.

16. Prior TW, Krainer AR, Hua Y, et al. A positive modifier of spinal muscular atrophy in the SMN2 gene. Am J Hum Genet 2009;85:408-413.

17. Vezain M, Saugier-Veber P, Goina E, et al. A rare SMN2 variant in a previously unrecognized composite splicing regulatory element induces exon 7 inclusion and reduces the clinical severity of spinal muscular atrophy. Hum Mutat 2010;31 E1110-E1125.

18. Vidal-Folch N, Gavrilov D, Raymond K, et al. Multiplex droplet digital PCR method applicable to newborn screening, carrier status, and assessment of spinal muscular atrophy. Clin Chem 2018;64:1753-1761.

19. Chen X, Sanchis-Juan A, French CE, et al. Spinal muscular atrophy diagnosis and carrier screening from genome sequencing data. Genet Med 2020;22:945-953.

20. Ruhno C, McGovern VL, Avenarius MR, et al. Complete sequencing of the SMN2 gene in SMA patients detects SMN gene deletion junctions and variants in SMN2 that modify the SMA phenotype. Hum Genet 2019;138:241-256.

21. Blasco-Pérez L, Paramonov I, Iranzo L, et al. SMN2 genes study by NGS in spinal muscular atrophy:towards identification of new SMA modifiers. Eur J Hum Genet ESHG Congr 2020. Interactive e-poster session P10.53.C. 
22. Anhuf D, Eggermann T, Rudnik-Schöneborn S, Zerres K. Determination of SMN1 and SMN2 copy number using TaqMan technology. Hum Mutat 2003;22:74-78.

23. Gómez-Curet I, Robinson KG, Funanage VL, Crawford TO, Scavina M, Wang W. Robust quantification of the SMN gene copy number by real-time TaqMan PCR. Neurogenetics 2007;8:271-278.

24. Kraszewski JN, Kay DM, Stevens CF, et al. Pilot study of population-based newborn screening for spinal muscular atrophy in New York state. Genet Med 2018;20: 608-613.

25. Feldkötter M, Schwarzer V, Wirth R, Wienker TF, Wirth B. Quantitative analyses of SMN1 and SMN2 based on real-time lightCycler PCR: fast and highly reliable carrier testing and prediction of severity of spinal muscular atrophy. Am J Hum Genet 2002; 70:358-368.

26. Cuscó I, Barceló MJ, Rojas-García R, et al. SMN2 copy number predicts acute or chronic spinal muscular atrophy but does not account for intrafamilial variability in siblings. J Neurol 2006;253:21-25.

27. Arkblad EL, Darin N, Berg K, et al. Multiplex ligation-dependent probe amplification improves diagnostics in spinal muscular atrophy. Neuromuscul Disord 2006;16: 830-838.

28. Stabley DL, Harris AW, Holbrook J, et al. SMN1 and SMN2 copy numbers in cell lines derived from patients with spinal muscular atrophy as measured by array digital PCR. Mol Genet Genomic Med 2015;3:248-257.

29. Zhong Q Bhattacharya S, Kotsopoulos S, et al. Multiplex digital PCR: breaking the one target per color barrier of quantitative PCR. Lab Chip 2011;11: 2167-2174.

30. Grotto S, Cuisset J-M, Marret S, et al. Type 0 spinal muscular atrophy: further delineation of prenatal and postnatal features in 16 patients. J Neuromuscul Dis 2016; 3:487-495.

31. Mendonça RH, Rocha AJ, Lozano-Arango A, et al. Severe brain involvement in $5 \mathrm{q}$ spinal muscular atrophy type 0. Ann Neurol 2019;86:458-462.
32. Cuscó I, Barceló MJ, Del Rio E, et al. Characterisation of SMN hybrid genes in Spanish SMA patients: de novo, homozygous and compound heterozygous cases. Hum Genet 2001;108:222-229.

33. Sun Y, Grimmler M, Schwarzer V, Schoenen F, Fischer U, Wirth B. Molecular and functional analysis of intragenic SMN1 mutations in patients with spinal muscular atrophy. Hum Mutat 2005;25:64-71.

34. Kitaoka H, Shitara Y, Uchida Y, Kondo U, Omori I. Case of spinal muscular atrophy type 0 with mild prognosis. Pediatr Int 2020;62:106-107.

35. Glascock J, Sampson J, Connolly AM, et al. Revised recommendations for the treatment of infants diagnosed with spinal muscular atrophy via newborn screening who have 4 copies of SMN2. J Neuromuscul Dis 2020;7:97-100.

36. Müller-Felber W, Vill K, Schwartz O, et al. Infants diagnosed with spinal muscular atrophy and 4 SMN2 copies through newborn screening: opportunity or burden? J Neuromuscul Dis 2020;7:109-117.

37. Kariyawasam DST, Russell JS, Wiley V, Alexander IE, Farrar MA. The implementation of newborn screening for spinal muscular atrophy: the Australian experience. Genet Med 2020;22:557-565.

38. Darras BT, Crawford TO, Finkel RS, et al. Neurofilament as a potential biomarker for spinal muscular atrophy. Ann Clin Transl Neurol 2019;6:932-944.

39. Maretina MA, Zheleznyakova GY, Lanko KM, Egorova AA, Baranov VS, Kiselev AV. Molecular factors involved in spinal muscular atrophy pathways as possible diseasemodifying candidates. Curr Genomics 2018;19:339-355.

40. Finkel RS, Mercuri E, Darras BT, et al. Nusinersen versus sham control in infantileonset spinal muscular atrophy. N Engl J Med 2017;377:1723-1732.

41. Tizzano EF, Finkel RS. Spinal muscular atrophy: a changing phenotype beyond the clinical trials. Neuromuscul Disord 2017;27:883-889.

42. Dangouloff $\mathrm{T}$, Servais L. Clinical evidence supporting early treatment of patients with spinal muscular atrophy: current perspectives. Ther Clin Risk Manag 2019;15: 1153-1161. 


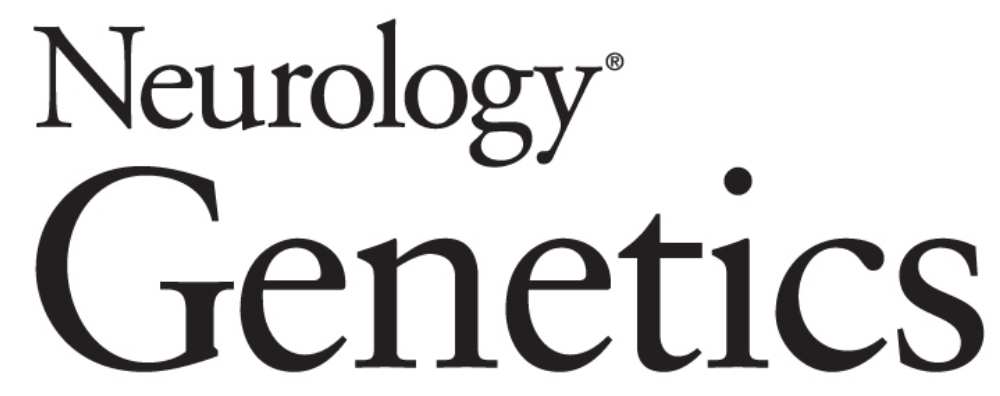

\section{Practical guidelines to manage discordant situations of $S M N 2$ copy number in patients with spinal muscular atrophy}

Ivon Cuscó, Sara Bernal, Laura Blasco-Pérez, et al.

Neurol Genet 2020;6;

DOI 10.1212/NXG.0000000000000530

This information is current as of November 11, 2020

\section{Updated Information \&}

Services

References

Citations

Permissions \& Licensing

Reprints including high resolution figures, can be found at: http://ng.neurology.org/content/6/6/e530.full.html

This article cites 41 articles, 2 of which you can access for free at: http://ng.neurology.org/content/6/6/e530.full.html\#\#ref-list-1

This article has been cited by 2 HighWire-hosted articles: http://ng.neurology.org/content/6/6/e530.full.html\#\#otherarticles

Information about reproducing this article in parts (figures,tables) or in its entirety can be found online at:

http://ng.neurology.org/misc/about.xhtml\#permissions

Information about ordering reprints can be found online: http://ng.neurology.org/misc/addir.xhtml\#reprintsus

Neurol Genet is an official journal of the American Academy of Neurology. Published since April 2015, it is an open-access, online-only, continuous publication journal. Copyright Copyright @ 2020 The Author(s). Published by Wolters Kluwer Health, Inc. on behalf of the American Academy of Neurology.. All rights reserved. Online ISSN: 2376-7839.

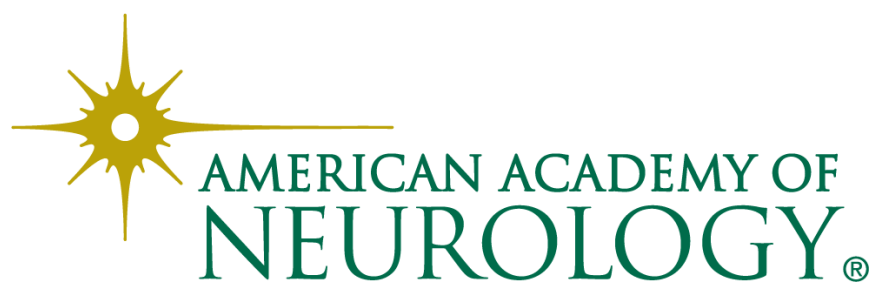

